\title{
Multiscale effects of flow regime and habitat and their interaction on fish assemblage structure in eastern Australia
}

\author{
Mark J. Kennard, Julian D. Olden, Angela H. Arthington, Bradley J. Pusey, \\ and N. LeRoy Poff
}

\begin{abstract}
We examine the multiscale influence of environmental and hydrological features of the riverine landscape on spatial and temporal variation in fish assemblages in eastern Australia. Multiresponse artificial neural network models provided accurate predictions of fish assemblages in the Mary River based on species presence-absence data (mean Bray-Curtis similarity between predicted and observed composition $=84 \%$ ) but were less accurate when based on species relative abundance or biomass (mean similarity $=62 \%$ and $59 \%$, respectively). Landscape- and local-scale habitat variables (e.g., catchment area and riparian canopy cover) and characteristics of the long-term flow regime (e.g., variability and predictability of flows) were more important predictors of fish assemblages than variables describing the short-term history of hydrological events. The relative importance of these variables was broadly similar for predicting species occurrence, relative abundance, or biomass. The transferability of the Mary River predictive models to the nearby Albert River was high for species presence-absence (i.e., closer match between predicted and observed data) compared with species abundances or biomass. This suggests that the same landscape-scale features are important determinants of distribution of individual species in both rivers but that interactions between landscape, hydrology, and local habitat features that collectively determine abundance and biomass may differ.
\end{abstract}

Résumé : Nous examinons à des échelles multiples l'influence des caractéristiques environnementales et hydrologiques d'un paysage de rivière sur la variation spatiale et temporelle des peuplements de poissons en Australie orientale. Des modèles de réseau neural artificiel à réponses multiples génèrent des prédictions précises des peuplements de poissons dans la rivière Mary à partir des données de présence et d'absence des espèces (similarité moyenne de Bray-Curtis entre les compositions prédites et observées $=84 \%$ ), mais elles sont moins exactes lorsqu'elles se basent sur l'abondance relative ou la biomasse des espèces (similarités moyennes respectives de $62 \%$ et de $59 \%$ ). Les variables à l'échelle du paysage ou à l'échelle locale (par ex., la surface du bassin versant et la couverture de la canopée de la rive) et les caractéristiques du régime d'écoulement à long terme (par ex., la variabilité et la prédictibilité des débits) sont de meilleures variables explicatives des peuplements de poissons que les variables qui décrivent le déroulement à court terme d'événements hydrologiques. L'importance relative de ces variables est grosso modo semblable pour la prédiction de la présence, de l'abondance relative et de la biomasse des espèces. Les modèles prédictifs mis au point sur la rivière Mary peuvent être utilisés sur la rivière Albert avoisinante avec plus de succès (c'est-à-dire avec un meilleur accord entre les valeurs prédites et observées) dans le cas de la présence-absence des espèces que dans celui des abondances et des biomasses des espèces. Ces observations indiquent que les mêmes facteurs à l'échelle du paysage sont importants dans la détermination de la répartition des espèces individuelles dans les deux rivières, mais que les interactions entre le paysage, l'hydrologie et les caractéristiques locales de l'habitat qui déterminent ensemble l'abondance et la biomasse peuvent être différentes.

[Traduit par la Rédaction]

\section{Introduction}

Understanding the mechanisms that structure riverine communities requires a multiscale approach that recognizes the nested physical hierarchy of natural river systems (Fausch et al. 2002; Lowe et al. 2006). Ecological patterns observed at small scales are the product of both local habitat structure and dynamics and constraints imposed at broader spatial and tem-

Received 29 September 2006. Accepted 4 June 2007. Published on the NRC Research Press Web site at cjfas.nrc.ca on 29 September 2007.

J19564

M.J. Kennard, ${ }^{1}$ A.H. Arthington, and B.J. Pusey. Australian Rivers Institute and eWater Cooperative Research Centre, Griffith University, Nathan, QLD 4111, Australia.

J.D. Olden. School of Aquatic and Fishery Sciences, Box 355020, University of Washington, Seattle, WA 98195, USA.

N.L. Poff. Department of Biology and Graduate Degree Program in Ecology, Colorado State University, Fort Collins, CO 80523, USA.

${ }^{1}$ Corresponding author (e-mail: m.kennard@griffith.edu.au). 
poral scales. In this context, riverine flow regimes are a key driver of lotic ecosystem structure and function (Poff et al. 1997; Bunn and Arthington 2002) and their hierarchical influence may be manifested at multiple spatial and temporal scales (Biggs et al. 2005). Long-term variations in flow magnitude, and the timing, frequency, and duration of flow events, define the physical habitat template over large spatial scales (e.g., catchments and subcatchments), whereas the short-term history of hydrological events influences habitat availability and connectivity at smaller spatial scales (e.g., within and among river reaches). These factors collectively influence the availability of refuges, food resources, opportunities for movement and migration, and conditions suitable for spawning and recruitment of fish and other biota (e.g., Schlosser 1991; Humphries et al. 1999; Magoulick and Kobza 2003).

To date, many of the hierarchical linkages in riverine ecosystems are poorly understood and inadequately validated and remain expressed largely as descriptive hypotheses rather than as predictive or quantitative models. In this paper, we use a hierarchical conceptual framework to address two issues that have impeded efforts to link variation in local fish assemblages to the independent and interactive effects of hydrological variation with the physical features of stream channels at multiple scales. First, the utility of multiscaled approaches is increasingly recognised, yet few empirical studies have explicitly attempted to characterise environmental processes influencing local assemblages simultaneously through both space and time (Lowe et al. 2006). Typically, species-environment relationships are evaluated at one or more spatial or temporal scales, but not both (Jackson et al. 2001). Second, the manner in which biological assemblages are characterised may influence the strength and nature of species-environment relationships detected (Cushman and McGarigal 2004); however, this has received little attention in studies of aquatic ecosystems. For example, species occurrence at a particular location and time may be due to a combination of large-scale factors (e.g., climate and catchment morphology), whereas the relative abundance or biomass of species in an assemblage is more likely driven by processes operating at the local scale (Rahel 1990).

We conducted our study in a region of eastern Australia characterised by highly variable and unpredictable flow regimes and, hence, challenging conditions for predictive model development (Pusey et al. 2000; Kennard et al. 2006a). Spatial and temporal patterns of fish assemblage structure in the Mary River, southeastern Queensland, were expressed as three biotic measures (species presenceabsence, species relative abundance, and species relative biomass). These measures were modelled as a function of a hierarchy of environmental and hydrological variables using multiresponse artificial neural networks (Olden 2003). We then tested the transferability of the Mary River predictive models on a smaller set of independent data from the nearby Albert River. Our ultimate objectives were to gain insight into the relative influence of multiscaled environmental and hydrological features of the riverine landscape on different properties of fish assemblages and to evaluate the generality of these relationships among nearby catchments.

\section{Materials and methods}

\section{Study area}

Southeastern Queensland, Australia, is a region of transitional temperate to subtropical climate constituting a single freshwater fish biogeographic region (Unmack 2001). The majority of rainfall and streamflow occur in the summer months of January to March, often followed by a second minor discharge peak between April and June. Inter- and intraannual variation in discharge is substantial, where high and low flows may occur at any time of year (Pusey et al. 2004). Our study systems, the Mary River $\left(9400 \mathrm{~km}^{2}\right)$ and LoganAlbert River $\left(4195 \mathrm{~km}^{2}\right)$ catchments, drain to the eastern coast of Australia and are bounded to the west by extensions of the Great Dividing Range (Fig. 1). Sampling sites were arrayed widely throughout each catchment (located on thirdto seventh-order streams and rivers) to encompass as much of the natural biological and environmental variation as possible. Sites were selected according to a stratified random sampling design (i.e., randomly stratified by relative position within the catchment), which was constrained by available access points to the river, water depth (see below), and a desire to avoid areas affected by human activity. Reaches chosen for study represented the best condition available (sensu Hughes 1995) (i.e., minimally disturbed riparian vegetation and bank and channel structure in natural condition), and the degree of flow regulation was minimal. Human impacts were therefore not expected to influence fish assemblage dynamics and relationships with flow and habitat described in our study. Sixteen sites in the Mary River were sampled seasonally (Austral winter, spring, and summer) on nine or 10 occasions between 1994 and 1997 ( $n=158$ samples). Eleven sites in the Albert River were sampled seasonally on six or seven occasions between 1995 and 1997 ( $n=71$ samples).

\section{Fish sampling}

Fish surveys were conducted in wadeable stream reaches ( $<1.5 \mathrm{~m}$ maximum depth). We avoided sampling immediately after high flow events, and on occasions when high flows occurred, we waited at least 2 weeks until flows had subsided and fish sampling could be conducted efficiently. Study sites were between $70 \mathrm{~m}$ and $80 \mathrm{~m}$ of stream length, usually constituting an entire meander wavelength or one riffle-run-pool sequence. We sampled three contiguous individual mesohabitat units (i.e., riffles, runs, or pools) within each reach and combined this data to represent each site. Each mesohabitat unit was blocked upstream and downstream with weighted seine nets (11 mm stretched-mesh) to prevent fish movement into or out of the study area. Fish assemblages were intensively sampled using multiple-pass electrofishing (Smith-Root model 12B Backpack Electrofisher; Smith-Root Inc., Vancouver, Wash.) and seine netting (11 mm stretched-mesh) (see Kennard et al. (2006b) for a complete description and evaluation of the sampling protocol). All fish collected were identified to species, counted, and measured (standard length to the nearest millimetre). Australian native fish were released at the point of capture, whereas nonindigenous species were sacrificed (using benzocaine) in accordance with the Queensland Fisheries Act (Queensland Parliamentary Council 1994). The weight of each fish was estimated by reference to published rela- 
Fig. 1. (a) Location of the study sites in two river basins in southeastern Queensland. The insets $(b)$ and $(c)$ show the location of the study area in Queensland, Australia.

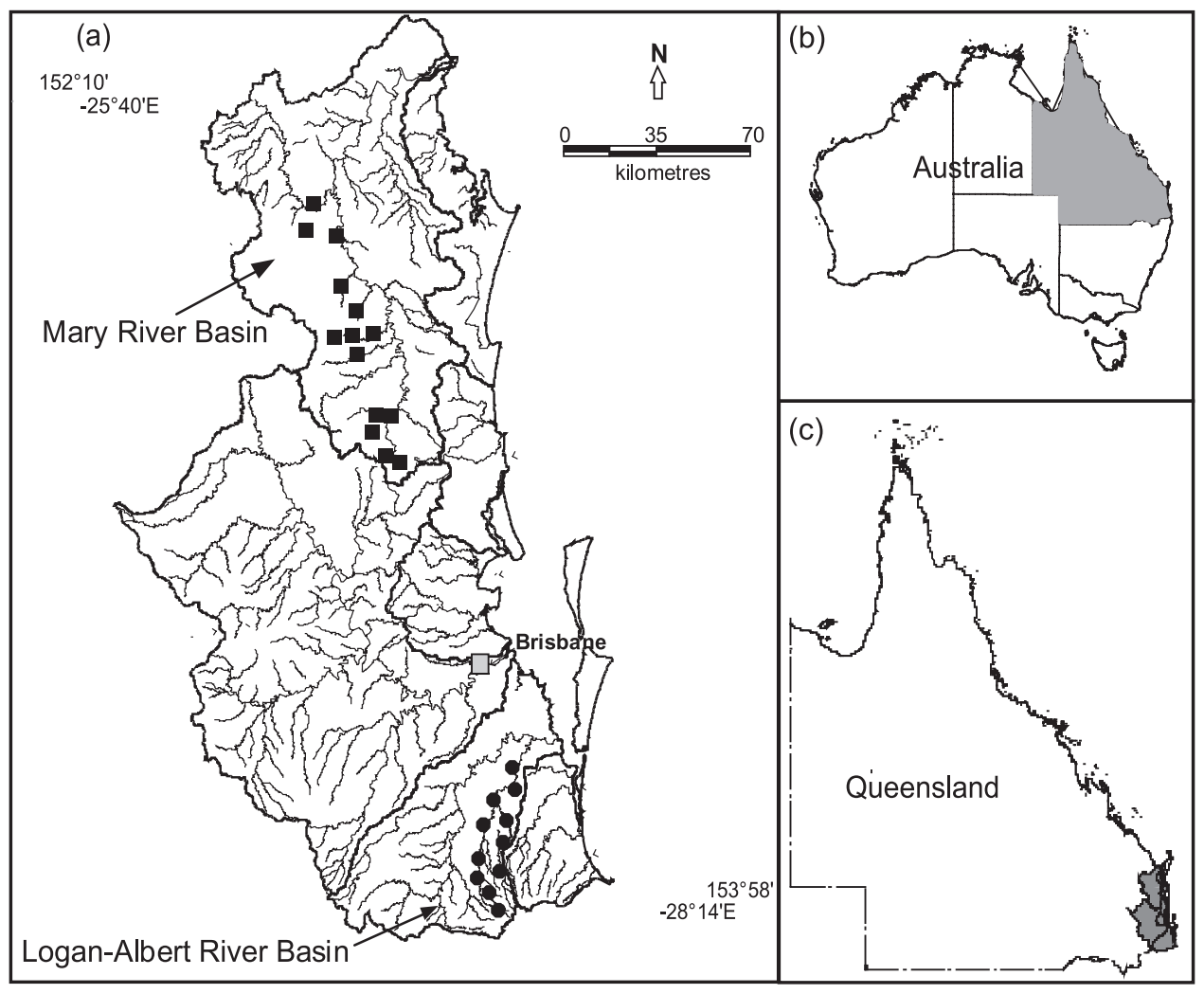

tionships between body length and mass for each species (Pusey et al. 2004). We calculated the following fish assemblage attributes for each site and sampling occasion: species composition (the presence or absence of species); species relative abundance (the percentage of the total number of individuals); and species relative biomass (the percentage of the total biomass of fish).

\section{Environmental and hydrological descriptors}

A set of the most ecologically relevant environmental and hydrological predictor variables were chosen from a larger number of candidate predictor variables derived from the literature and prior research in the study region (see Pusey et al. (2004) and references therein). Bivariate plots and Spearman's correlations among variables were used to identify and remove highly correlated variables. Spearman's correlation coefficients among the final set of predictor variables usually ranged between -0.5 and +0.5 . Two landscapescale variables and four local-scale variables were selected to describe environmental characteristics of the study sites (Table 1). The two landscape-scale variables (upstream catchment area and distance to the river mouth of each site) were estimated from 1:100 000 topographic maps using a digital planimeter. On each sampling occasion for each study site, the four local-scale environmental variables were measured or estimated using standard protocols described in Pusey et al. (2004). Mean wetted stream width, mean water velocity, and mean water depth were calculated from a series of 40- to 60-point measurements located randomly through- out the site. Mean riparian canopy cover was estimated from three site measurements using a spherical densometer.

We quantified antecedent flow conditions over three different time periods: long term (25 years), short term (the 4 months immediately preceding the time of sampling), and the preceding spawning season (September to March). The long-term hydrological record summarises conditions relating to disturbance regimes, aquatic habitat connectivity, overall habitat availability, and temporal variation in habitat structure and its spatial variability. We hypothesised that these factors were potentially important to fish via long-term temporal variation in individual species recruitment patterns and the frequency of local colonisation and extinction events. Short-term hydrological conditions indicate the presence of potential disturbance events prior to sampling, as well as the extent to which conditions at the time of sampling differ greatly from those in the preceding 4 months. The third group of flow attributes characterized spawning season conditions for the majority of fish species in southeastern Queensland (Pusey et al. 2004).

Six variables describing the long-term hydrological regime were calculated (Table 1). These included mean daily runoff (daily discharge standardised by upstream catchment area), variability (coefficient of variation) of daily flow, mean duration of zero flow events, and predictability of mean daily flow, minimum instantaneous flow, and maximum instantaneous flow in each month. Colwell's (1974) in$\operatorname{dex}(P)$ was used to quantify predictability in terms of a constancy factor $(C)$ and a contingency factor $(M)$, the sum 
Table 1. Means and 95\% confidence intervals (CI) for environmental and hydrological variables used as predictors in the neural network models developed for the Mary River and tested in the Albert River.

\begin{tabular}{|c|c|c|c|c|c|}
\hline \multirow[b]{2}{*}{ Predictor variables } & \multirow[b]{2}{*}{ Code } & \multicolumn{2}{|c|}{ Mary River (training data) } & \multicolumn{2}{|c|}{ Albert River (test data) } \\
\hline & & Mean & $95 \% \mathrm{CI}$ & Mean & $95 \% \mathrm{CI}$ \\
\hline \multicolumn{6}{|l|}{ Landscape-scale environment } \\
\hline Distance to river mouth $(\mathrm{km})$ & distm & 202.2 & $167.2,237.1$ & 77.0 & $57.8,96.2$ \\
\hline \multicolumn{6}{|l|}{ Long-term flow regime } \\
\hline Mean daily runoff $\left(\mathrm{ML} \cdot \mathrm{km}^{2}\right)$ & 1_mdr & 0.63 & $0.49,0.76$ & 0.83 & $0.73,0.92$ \\
\hline Predictability $(P)$ mean daily flow (month) & 1_pmndf & 0.22 & $0.19,0.25$ & 0.15 & $0.14,0.16$ \\
\hline Predictability $(P)$ minimum monthly flow & 1_pmidf & 0.16 & $0.13,0.19$ & 0.11 & $0.10,0.13$ \\
\hline Predictability $(P)$ maximum monthly flow & 1_pmxdf & 0.57 & $0.52,0.63$ & 0.40 & $0.37,0.44$ \\
\hline Mean duration of zero flow events (days) & 1_mdzf & 12.0 & $5.6,18.4$ & 0 & 0,0 \\
\hline \multicolumn{6}{|l|}{ Local-scale environment } \\
\hline \multicolumn{6}{|l|}{ Short-term flow history } \\
\hline No. of zero flow days, 4 months before sample & s_zfd & 18.6 & $13.5,23.7$ & 0 & 0,0 \\
\hline $\begin{array}{l}\text { No. of flow events greater than } 1.67 \text { annual return interval, } \\
4 \text { months before sample }\end{array}$ & s_hfe & 0.44 & $0.34,0.55$ & 0.54 & $0.37,0.70$ \\
\hline Mean daily runoff, 4 months before sample $\left(\mathrm{ML} \cdot \mathrm{km}^{2}\right)$ & s_mdr & 0.35 & $0.28,0.42$ & 1.02 & $0.72,1.32$ \\
\hline CV daily flow, 4 months before sample & s_cvd & 2.65 & $2.39,2.91$ & 2.01 & $1.72,2.29$ \\
\hline Mean daily runoff, spawning season before sample $\left(\mathrm{ML} \cdot \mathrm{km}^{2}\right)$ & s_mdrsp & 0.41 & $0.37,0.45$ & 0.51 & $0.45,0.57$ \\
\hline $\mathrm{CV}$ daily flow, spawning season before sample & s_cvdsp & 4.09 & $3.84,4.35$ & 3.28 & $2.96,3.60$ \\
\hline
\end{tabular}

Note: Variable abbreviations are used in Fig. 3. CV, coefficient of variation.

of which equals $P$. This index ranges from 0 (random) to 1 (totally predictable). We allocated discharge values to one of 11 flow classes with a central class of 20 times mean daily flow, using $\log _{2}$ classes (Marsh et al. 2003). We distinguish variability, which is insensitive to temporal pattern, from predictability, a measure of temporal uncertainty in periodic phenomena, and expect both to be ecologically important (Poff and Ward 1990; Pusey et al. 2000).

Short-term antecedent conditions (Table 1) were characterised by four variables: mean daily runoff, coefficient of variation of daily flow, number of zero flow days, and the number of high flow events (flow events greater than 1.67 year average recurrence interval) for the 4 months immediately preceding the time of sampling. We chose this high flow threshold as it approximates bankfull flow conditions and hence the flow magnitude yielding close to maximum water velocities, turbulence, shear stress, and stream power. The magnitude of the 1.67-year average recurrence interval flood was estimated from a 25 -year hydrological record at each site using the annual duration series. The flood event independence criterion was defined as 7 days for these calculations. Lastly, we characterized hydrological conditions prevailing over the spawning period prior to sampling by estimating the mean daily runoff and coefficient of variation of daily flow (Table 1).

All flow variables for each study site were derived using 25 years (1974-1997) of daily discharge data simulated us- ing integrated quantity and quality models (IQQM; Simons et al. 1996). IQQM, a tool used widely in Australia and elsewhere for water resource planning and assessment, can simulate flow volumes under various management scenarios including before water resource development, existing water use, and hypothetical future water demand. IQQM uses the Sacramento rainfall-runoff model based on rainfall and evaporation data for the generation of subcatchment runoff and operates on a continuous basis with a daily time step. IQQM parameters are determined by calibration against observed streamflow data (Simons et al. 1996; Merritt et al. 2003). IQQM for the Mary and Albert rivers were developed by the Queensland Department of Natural Resources and Water and were calibrated using daily flow data from 28 and 9 stream gauging stations in the Mary and Albert rivers, respectively (see Brizga et al. (2004, 2006) for further details on IQQM development and calibration). We used daily flow data simulated for existing water use (which was minimal for our study sites). Use of IQQM modelled flow data to estimate summary hydrological statistics for short temporal sequences (i.e., within-year) may be prone to greater error than when based on longer time series. We do not view this as being problematic in our study as all sampling sites were located within $20 \mathrm{~km}$ of stream gauges used to calibrate the IQQM developed for each river basin. Therefore, the temporal sequence of flows modelled by IQQM should accurately represent the existing pattern of flow as measured at the 
stream gauges. All flow variables were calculated using the river analysis package (Marsh et al. 2003).

\section{Statistical analyses}

\section{Multiresponse artificial neural network}

Species presence-absence, relative abundance, and relative biomass in the Mary River samples were modelled as a function of the 18 environmental and hydrological variables using a multiresponse artificial neural network (see Olden 2003; Olden et al. 2006a). In addition to the flexibility of neural networks to model multiple response variables, they are capable of modelling nonlinear associations with a variety of data types, require no specific assumptions concerning the distributional characteristics of the independent variables, and can accommodate interactions among predictor variables without any a priori specification (Bishop 1995). Neural networks have been shown to exhibit substantially higher predictive power (based on empirical and simulated data) when modelling nonlinear relationships compared with logistic regression, linear discriminant analysis, or classification trees (Olden and Jackson 2002).

We used feed-forward neural networks trained by the backpropagation algorithm to model spatial and temporal variation in three response variables: species presence or absence, relative abundance, and relative biomass. The architecture of these networks consisted of a single input, hidden, and output layers. The input layer contained one neuron for each of the environmental variables (18 in total). The number of neurons in the single hidden layer was chosen to minimize the trade-off between network bias and variance by comparing the performances of different cross-validated networks, with 2 to 50 hidden neurons (increasing by increments of 2), and choosing the number that produced the greatest external network performance. This resulted in the selection of 8,9 , and 14 hidden neurons for the modelling of species presence-absence, relative abundance, and relative biomass, respectively. The output layer contained one neuron for each fish species being modelled, representing either the probability of species presence-absence (decision threshold of 0.5), species relative abundance, or species relative biomass.

Model training involved the cross-entropy error function for species presence or absence (suitable for binary variables) and sums of squared error function for species relative abundance and biomass (suitable for continuous variables). Learning rate $(\eta)$ and momentum $(\alpha)$ parameters (varying as a function of network error) were included during network training to ensure a high probability of global network convergence and a maximum of 1000 iterations for the backpropagation algorithm to determine the optimal axon weights. We refer the reader to Olden (2003) and Olden et al. (2006a) for more methodological details. The contributions of the environmental and hydrological variables in the neural networks were quantified by calculating the product of the input-hidden and hidden-output connection weights between each input neuron and output neuron and then summing the products across all hidden neurons. This approach is deemed the most appropriate as it has been shown to outperform other techniques for quantifying variable contributions in neural networks (Olden et al. 2004). All neural network analyses were conducted using computer macros written in the MatLab ${ }^{\circledR}$ (The MathWorks, Natick, Massachusetts) programming language.

\section{Model validation and performance}

Model validation was conducted in two ways. First, $n$-fold cross validation was used to generate model predictions and assess classification performance of the neural networks based on the Mary River data. This validation method excludes one observation, constructs the model with the remaining $n-1$ observations, predicts the response of the excluded observation using this model, and repeats the procedure $n$ times. Second, external validation was conducted by using the Mary River neural networks to predict the fish assemblages in the Albert River samples. This analysis provided an opportunity to assess the generality or transferability of the Mary River models to other river systems within the same biogeographic region in eastern Australia. Model performance for species presence-absence was assessed by calculating three metrics: overall classification performance (percentage of sites where the model correctly predicts species presence-absence), sensitivity (percentage of the sites where species presence was correctly predicted), and specificity (percentage of the sites where species absence was correctly predicted) (see Fielding and Bell 1997). Model performance for species relative abundance and biomass was assessed using Pearson's product-moment correlation coefficient $(r)$ (a measure of prediction accuracy) and root mean square error (RMSE) (a measure of prediction precision). We assessed the statistical significance of species predictions following the protocols of Olden et al. (2002). Null distributions of correct classification rates (CCRs) for each species presence-absence were generated by randomly permuting the original observations among the stream sites, constructing an artificial neural network using the randomized data and the original environmental variables, and calculating the CCR (based on $n$-fold validation). This procedure was then repeated 9999 times and the significance level of the predictive model was calculated as the proportion of random CCRs (including the observed CCR) that were larger than or equal to the observed CCR. The randomization test was repeated for species relative abundance and biomass using the correlation coefficient $(r)$. We assessed the overall performance of the neural network models by calculating the degree of concordance between predicted and observed fish assemblages (defined by species presence-absence, relative abundance, and biomass) using the Bray-Curtis similarity coefficient (Krebs 1999).

\section{Results}

\section{Characteristics of the fish fauna and the riverine environment}

Twenty-five fish species from 13 families were collected in the Mary River, 18 of which were also present in the Albert River (Table 2). Fourteen species, each representing greater than $1 \%$ of the relative abundance, were used for prediction of species relative abundance and biomass. Although fish assemblage characteristics varied between the two rivers, there were significant correlations among rivers in terms of species frequency of occurrence (Pearson's $r=$ 
Table 2. Characteristics of the fish fauna in Mary River and Albert River.

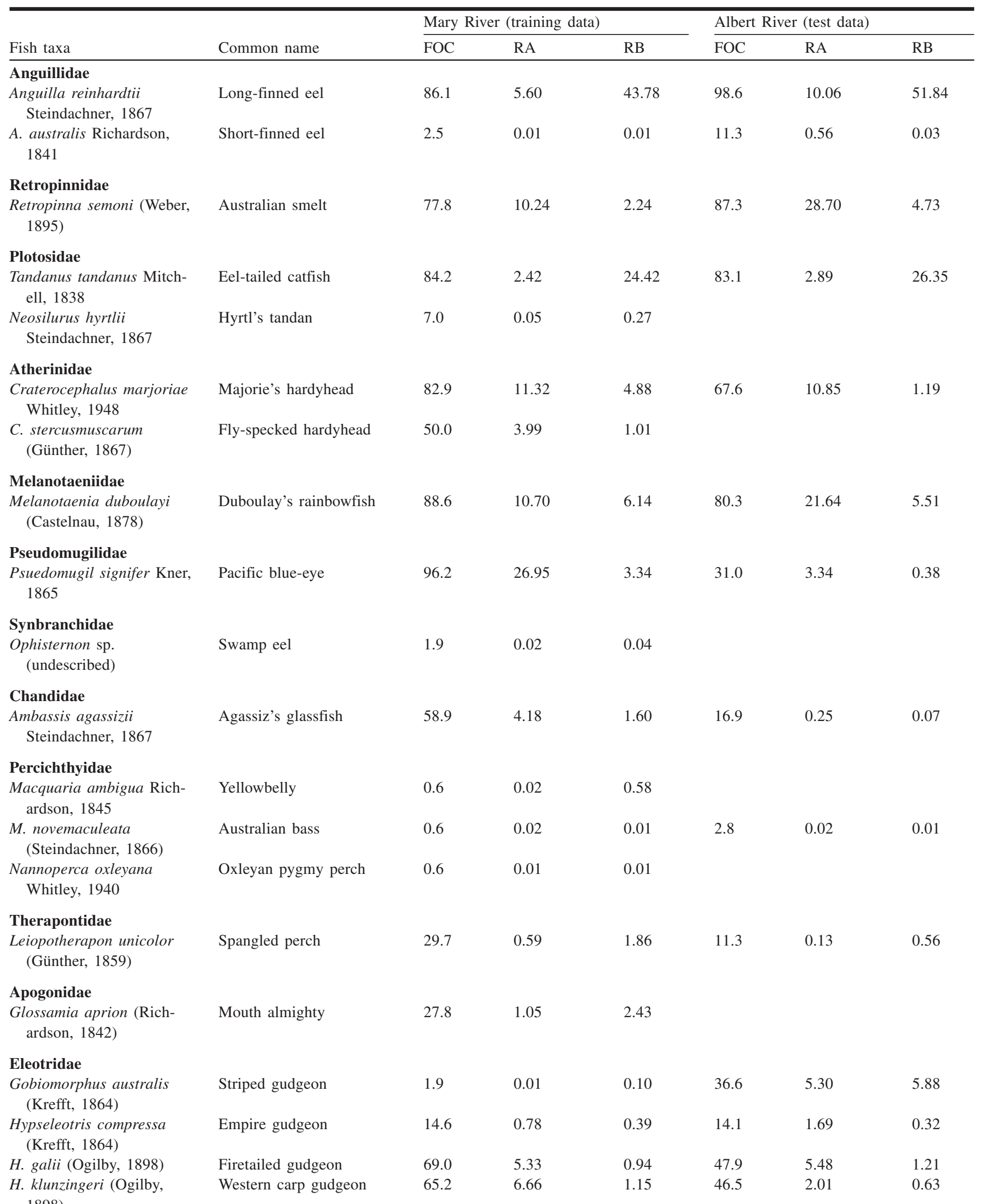
1898) 
Table 2 (concluded).

\begin{tabular}{|c|c|c|c|c|c|c|c|}
\hline \multirow[b]{2}{*}{ Fish taxa } & \multirow[b]{2}{*}{ Common name } & \multicolumn{3}{|c|}{ Mary River (training data) } & \multicolumn{3}{|c|}{ Albert River (test data) } \\
\hline & & FOC & RA & $\mathrm{RB}$ & FOC & RA & $\mathrm{RB}$ \\
\hline $\begin{array}{r}\text { Mogurnda adspersa } \\
\text { (Castelnau, 1878) }\end{array}$ & Purple-spotted gudgeon & 57.6 & 1.67 & 1.63 & & & \\
\hline $\begin{array}{r}\text { Philypnodon sp. } \\
\text { (undescribed) }\end{array}$ & Dwarf flathead gudgeon & 43.0 & 0.72 & 0.26 & 16.9 & 0.41 & 0.09 \\
\hline $\begin{array}{l}\text { P. grandiceps (Krefft, } \\
\text { 1864) }\end{array}$ & Flathead gudgeon & 41.1 & 0.87 & 0.71 & 19.7 & 0.49 & 0.37 \\
\hline $\begin{array}{l}\text { Gambusia holbrooki } \\
\text { (Girard, 1859)* }\end{array}$ & Eastern mosquitofish & 36.1 & 4.82 & 1.25 & 53.5 & 6.02 & 0.75 \\
\hline \multirow{2}{*}{$\begin{array}{c}\text { Xiphophorus helleri } \\
\text { Heckel, 1848* }\end{array}$} & Swordtail & 17.7 & 1.97 & 0.96 & 8.5 & 0.19 & 0.08 \\
\hline & & Samples & Individuals & Biomass & Samples & Individuals & Biomass \\
\hline
\end{tabular}

Note: The frequency of occurrence (FOC), relative abundance (RA), and relative biomass (RB) of each species are shown for each river. These data are expressed as percentages of the total $(n)$ number of samples, total number of individuals, and total biomass (kg) of fish collected in each river, respectively. Fish families are arranged in approximate phylogenetic order (after Pusey et al. 2004). An asterisk (*) indicates nonindigenous species.

$0.74, p<0.001)$, relative abundance $(r=0.47, p<0.05)$, and relative biomass $(r=0.95, p<0.001)$ (Table 2$)$. The range of variation in environmental and hydrological conditions at the Mary River sites was generally similar to, or greater than, the range at Albert River sites (Table 1). This implies that fish should respond in similar ways to environmental and hydrological conditions in each river and therefore that a predictive model developed for the Mary River may have the capacity to predict fish assemblages in the Albert River. The major exception was that sites in the Albert River were situated relatively closer to the river mouth than sites in the Mary River, primarily because the Albert River catchment is smaller in size. The predictability of mean and maximum flows, and the incidence of zero flows, were lower in the Albert River. Mean daily runoff prior to sampling was usually higher and the variability of daily flows was usually lower in the Albert River than in the Mary River (Table 1).

\section{Species-level model performance}

The neural network model exhibited high success in predicting individual species presence or absence in the Mary River samples (Table 3). Mean correct classification rate was $87.3 \%$, where 20 of the 25 species were correctly classified $(p<0.05)$ and all but one species (Hypseleotris klunzingeri) had correct classification rates exceeding $77 \%$. Overall, the model was better able to correctly predict the absence of species than their presence (mean specificity $=76.2 \%$ and mean sensitivity $=60 \%$ ), an expected result given the low frequency of occurrence of many species in the data set. The model had difficulty predicting the presence of rare species (i.e., low sensitivity) and the absence of some widespread species (low specificity). For example, those species present in less than $3 \%$ of samples were never correctly predicted (sensitivity values $=0 \%$ ), and the five most widespread species (blue-eye (Psuedomugil signifer), rainbowfish (Melanotaenia duboulayi), eel (Anguilla reinhardtii), catfish (Tandanus tandanus), and hardyhead (Craterocephalus marjoriae)) present in more than $82 \%$ of samples had among the lowest specificity values (50\% or less) (Table 3). When applied to the Albert River sites, the Mary River model did not perform as effectively. Although the mean correct classification rate across all 25 species was $73 \%$, only 12 of the 25 species were correctly classified $(p<0.05)$. Mean specificity $(56.8 \%)$ and sensitivity $(57.0 \%)$ values were also lower for the Albert River data set than for the Mary River data set (Table 3).

The predictive model of species relative abundances was moderately accurate in the Mary River. The abundances of six of the 14 species modelled could be accurately predicted ( $p<0.05$ ), although correlations (Pearson's $r$ values) between predicted and observed values were greater than 0.5 for nine of the 14 species examined (Table 3 ). The neural network based on species relative biomass was less accurate, however, with predictions of individual species biomass being significant for only two species and $r$ values being generally low (Pearson's $r>0.5$ in only 2 of 14 species). Predictions of species abundance and biomass data for Albert River were less accurate than for Mary River. The abundance and biomass of three species and of one species, respectively, were significantly predicted in the Albert River, but correlations between observed and expected values were less than 0.5 in all but one species comparison. No consistent pattern in the precision (as assessed by RMSE values) of species predictions was evident between rivers or assemblage data type (abundance versus biomass) (Table 3), and the predictive accuracy and precision appeared unrelated to the overall relative abundance or biomass of each species in the data set (Tables 2 and 3).

\section{Assemblage-level model performance}

Assessments at the assemblage level showed that the neural network predictions of fish species composition (based on presence-absence data) in the Mary River were highly concordant with observed composition. Mean Bray-Curtis similarity between predicted and observed species composition was $84.3 \%$, and nine-tenths of samples contained fish assemblages that were greater than $70 \%$ similar to those predicted (Fig. 2). Model performance for assemblage estimates of relative abundance and biomass were lower, where mean 


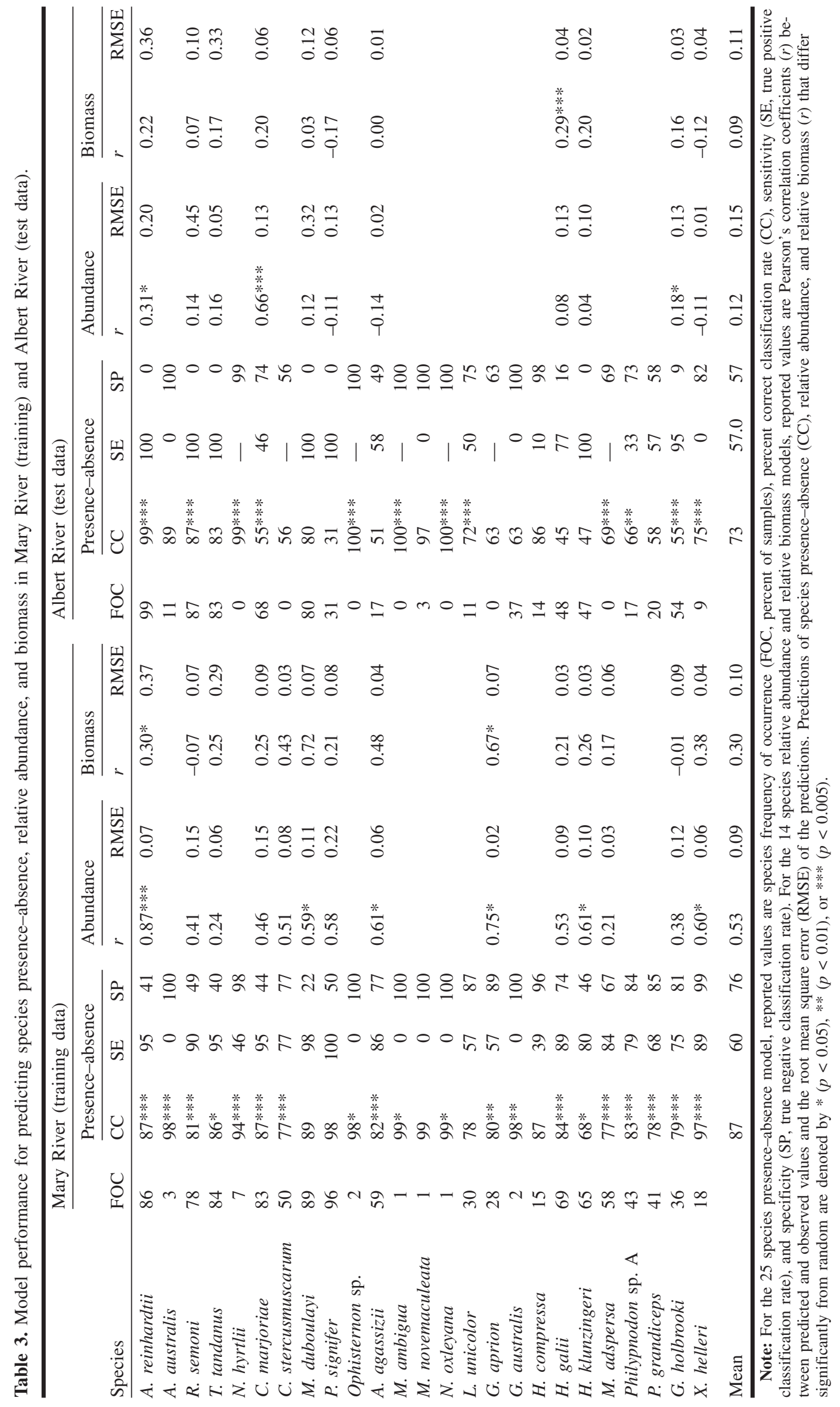


Fig. 2. Comparison of overall accuracy of artificial neural network (ANN) models to predict fish assemblages based on presenceabsence (P/A, solid bars), relative abundance (AB, hatched bars), and relative biomass (BM, open bars) data for $(a)$ Mary River (training data) and (b) Albert River (test data). Histograms are frequency distributions (percentage of samples) of Bray-Curtis similarities between fish assemblages predicted by ANN models and those observed using the same 14 species in each data set. Arrows represent the mean Bray-Curtis similarity.

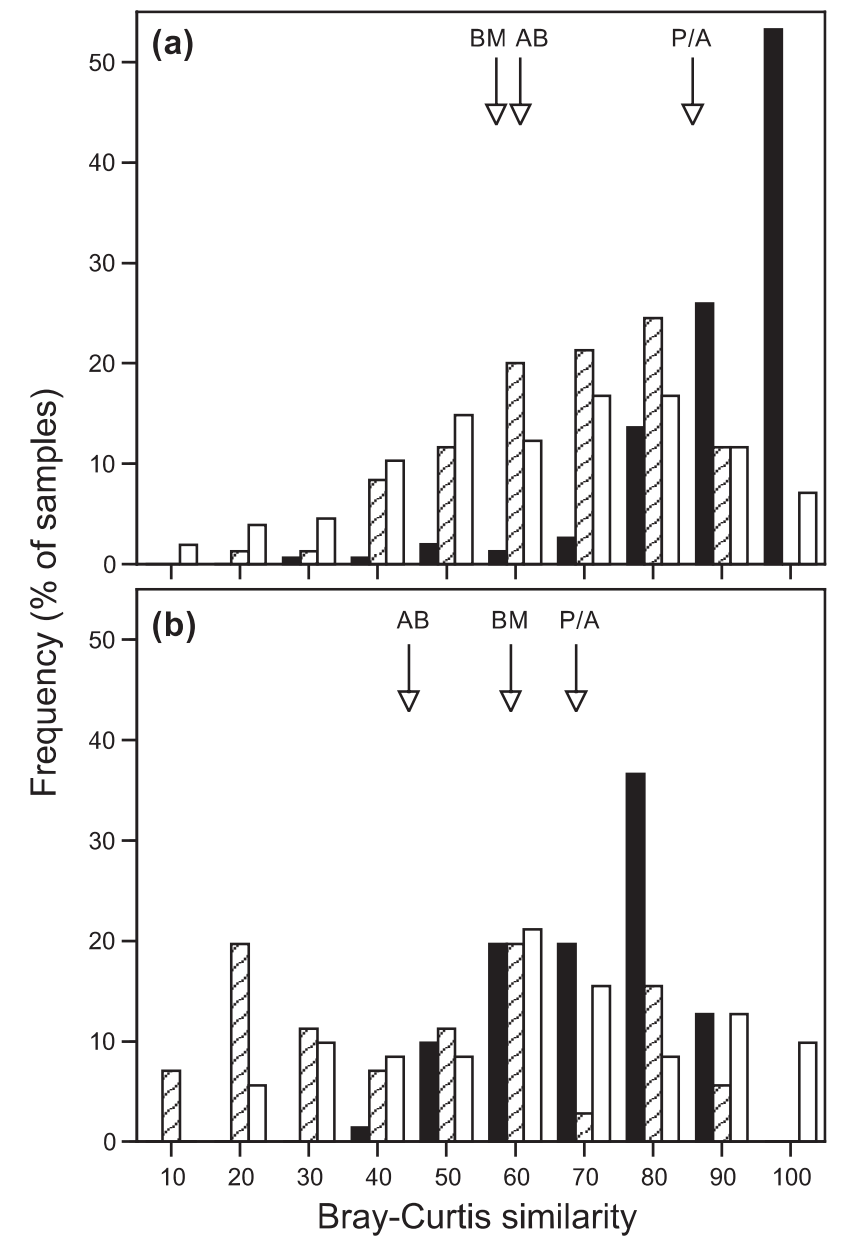

Bray-Curtis similarity between predicted and observed species assemblage structure was $62 \%$ and $59 \%$, respectively. For both data sets, one-half of samples contained fish assemblages that were greater than $70 \%$ similar to predicted assemblages. In summary, a closer match between predicted and observed assemblages was observed for species presence-absence data than for species abundance or biomass data, the latter data being predicted with generally equivalent accuracy in the Mary River (Fig. 2). In all cases, model performance was greater for Mary River sites than for Albert River sites (Fig. 2).

\section{Environmental and hydrological drivers of fish assemblage structure}

Large- and local-scale environmental variables were important predictors of species occurrences in the Mary River
Fig. 3. Relative contributions of environmental and hydrological variables for predicting fish assemblages based on (a) presenceabsence, $(b)$ relative abundance, and $(c)$ relative biomass data averaged ( \pm 1 standard deviation) across the 14 fish species common to each artificial neural network (ANN) model. Open portions of each bar represent the relative frequency with which each predictor variable had a positive influence on species predictions, and solid portions of each bar indicate the relative frequency of negative influences on species predictions. Codes are defined in Table 1.
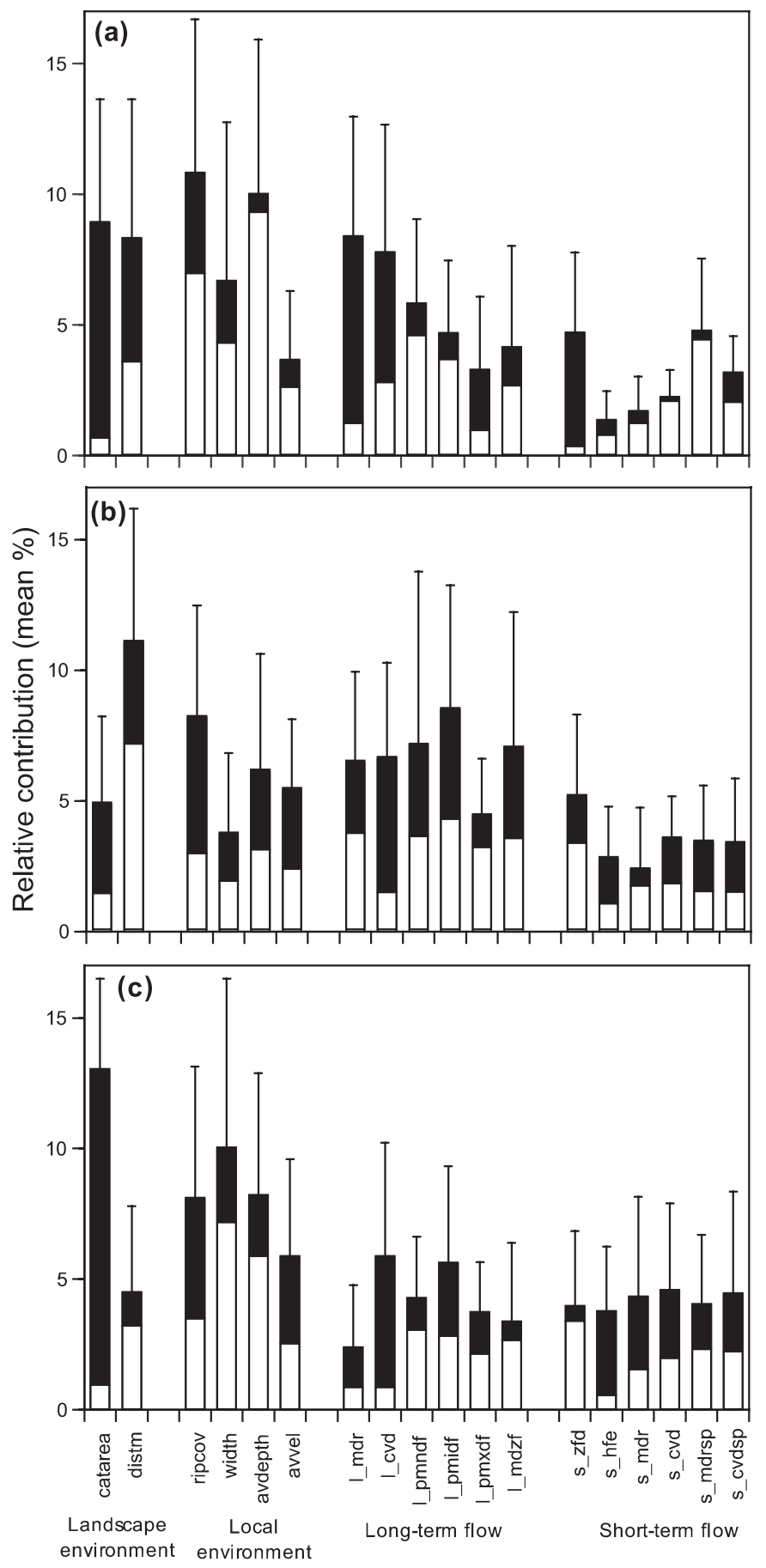

Predictor variable set 
(Supplemental Table S1). ${ }^{2}$ Catchment area and distance to river mouth were relatively important predictors (mean relative contribution $=8 \%$ and $9 \%$, respectively) of the total variation in assemblage composition. Three of the four local environmental variables (riparian cover, stream width, and mean depth of channel) were also important predictors $(>5 \%)$ of the total variation. Increasing catchment area and distance from river mouth typically had a negative influence on the predicted presence of a species, whereas the localscale environmental variables usually had a positive effect (Supplemental Table S1). ${ }^{2}$ Characteristics of the long-term flow regime were also important predictors of assemblage composition, particularly mean daily runoff, coefficient of variation of daily flow, the predictability (Colwell's $P$ ) of mean daily flow, and predictability of minimum instantaneous flow. Overall, short-term flow variables were comparatively less influential (mean relative contribution $<5 \%$ ), except those describing mean daily runoff during the spawning season before sampling and the number of zero flow days during the 4 months before fish collection.

Comparison of variables for predicting species composition (Supplemental Table S1), ${ }^{2}$ relative abundance (Supplemental Table S2), ${ }^{2}$ and relative biomass (Supplemental Table $\mathrm{S} 3)^{2}$ across the 14 species common to each model (Fig. 3) revealed similar patterns in the major classes of important predictor variables. However, some variation in the importance of individual variables within each class of predictors was evident. Landscape environment, local environment, and long-term flow variables were comparatively more important than short-term flow variables in predicting each biological response data set. However, catchment area and stream width were stronger predictors of variation in species relative biomass than species composition and abundance (Fig. 3). The importance of long-term flow predictability was comparatively higher for species relative abundances in comparison with the other fish assemblage data sets. Furthermore, most aspects of short-term flow history assumed generally equal importance for species relative biomass in comparison with only one or two variables dominating within this class of predictors for species composition and relative abundances.

The magnitude and direction of connection weights in the neural network (Fig. 4) reveal nonlinear species-environment relationships. We highlight several examples in which strong variable interactions were important for model predictions of fish assemblage composition. Some of the linkages demonstrate the importance of interactions between long-term flow and local-scale habitat structure. For example, note the interaction between variability of daily flows (long-term) and water depth via hidden neuron $\mathrm{G}$ for eels (A. reinhardtii), smelt (Retropinna semoni), catfish ( $T$. tandanus), rainbowfish (M. duboulayi), blue-eyes ( $P$. signifer), and mouth almighty (Glossamia aprion). Increasing variability of daily flows decreased the probability of occurrence of these species, except in deeper sites. Landscape-scale factors (e.g., catchment area) were revealed by our model to influence species composition of assemblages via interactions with the predictability of minimum monthly flow (long-term) through hidden neuron F. Increased predictability of these minimum flows increased the probability of occurrence of three gudgeons ( $H$. galii and Philypnodon spp.), except in large subcatchments. A synergistic interaction between coefficient of variation (CV) of daily flow (long-term), number of zero flow days (shortterm), and stream width through hidden neuron D is evident for many species. Increasing variability of daily flow coupled with increasing duration of zero flows in wider streams decreased the probability of occurrence of glass perchlets (Ambassis agassizii) and three species of gudgeons (H. galii and Philypnodon spp.). We also found an interaction between two short-term flow variables (mean daily runoff during the spawning season with $\mathrm{CV}$ of daily flow during the spawning season) through hidden neuron $\mathrm{B}$ for the gudgeon $H$. klunzingeri and the nonindigenous species Gambusia holbrooki. Increasing mean daily runoff during the spawning season increased the probability of occurrence of these species, except when runoff was highly variable.

\section{Discussion}

This study aimed to gain insight into the relative influence of multiscaled environmental and hydrological features of the riverine landscape on different properties of fish assemblages and to evaluate the generality of these relationships among nearby catchments. Multiscaled approaches such as ours should be well suited to the study of riverine fish. Compared with other aquatic biota, fish are long-lived and mobile and so may occupy a variety of habitats and hence may encounter a range of environmental conditions throughout their life span (Fausch et al. 2002). However, these ecological factors, together with the complex hierarchical linkages evident in natural river ecosystems, can make it difficult to develop accurate predictive models and to isolate the importance of individual and interacting environmental controls on fish assemblages (Rose 2000).

The multispecies model for the Mary River provided accurate predictions of individual species occurrences (high mean correct classification rate) and assemblage composition (high similarity between predicted and observed assemblages). The important landscape- and local-scale environmental factors identified by this model are wellestablished correlates of, or are related mechanistically to, species distributions and fish assemblage composition in many river systems (Jackson et al. 2001). Attributes of the long-term flow regime were also important predictors of assemblage composition and likely govern the temporal availability and predictability of suitable habitat for various fish species. Long-term flow conditions also determine the spatial variability and connectivity of habitats that, in turn, influence local colonisation and extinction events (Magoulick and Kobza 2003; Matthews and Marsh-Matthews 2003; Scheurer et al. 2003).

The neural network provided significant insight into the important interactions among environmental and hydro-

\footnotetext{
${ }^{2}$ Supplementary data for this article are available on the journal Web site (http://cjfas.nrc.ca) or may be purchased from the Depository of Unpublished Data, Document Delivery, CISTI, National Research Council Canada, Building M-55, 1200 Montreal Road, Ottawa, ON K1A 0R6, Canada. DUD 5216. For more information on obtaining material refer to http://cisti-icist.nrc-cnrc.gc.ca/irm/unpub_e.shtml.
} 
Fig. 4. Neural interpretation diagram showing linkages between environmental and hydrological variables used for predicting fish species composition in Mary River. Line thickness is proportional to the magnitude of the axon connection weight, and line type indicates the direction of the interaction between neurons: solid line, connections are positive (excitators); broken line, connections are negative (inhibitors). Only statistically significant connection weights are presented $(p<0.05)$. Individual species with no output connections were not accurately predicted. Multiplication of the two connection weight directions (positive or negative) indicates the effect that each input variable has on the response variable (fish). Input variables with larger connection weights are more important in predicting the output compared with variables with smaller weights. CV, coefficient of variation; Pred., predictability; Min., minimum; Mx., maximum; Dur., duration (mean).

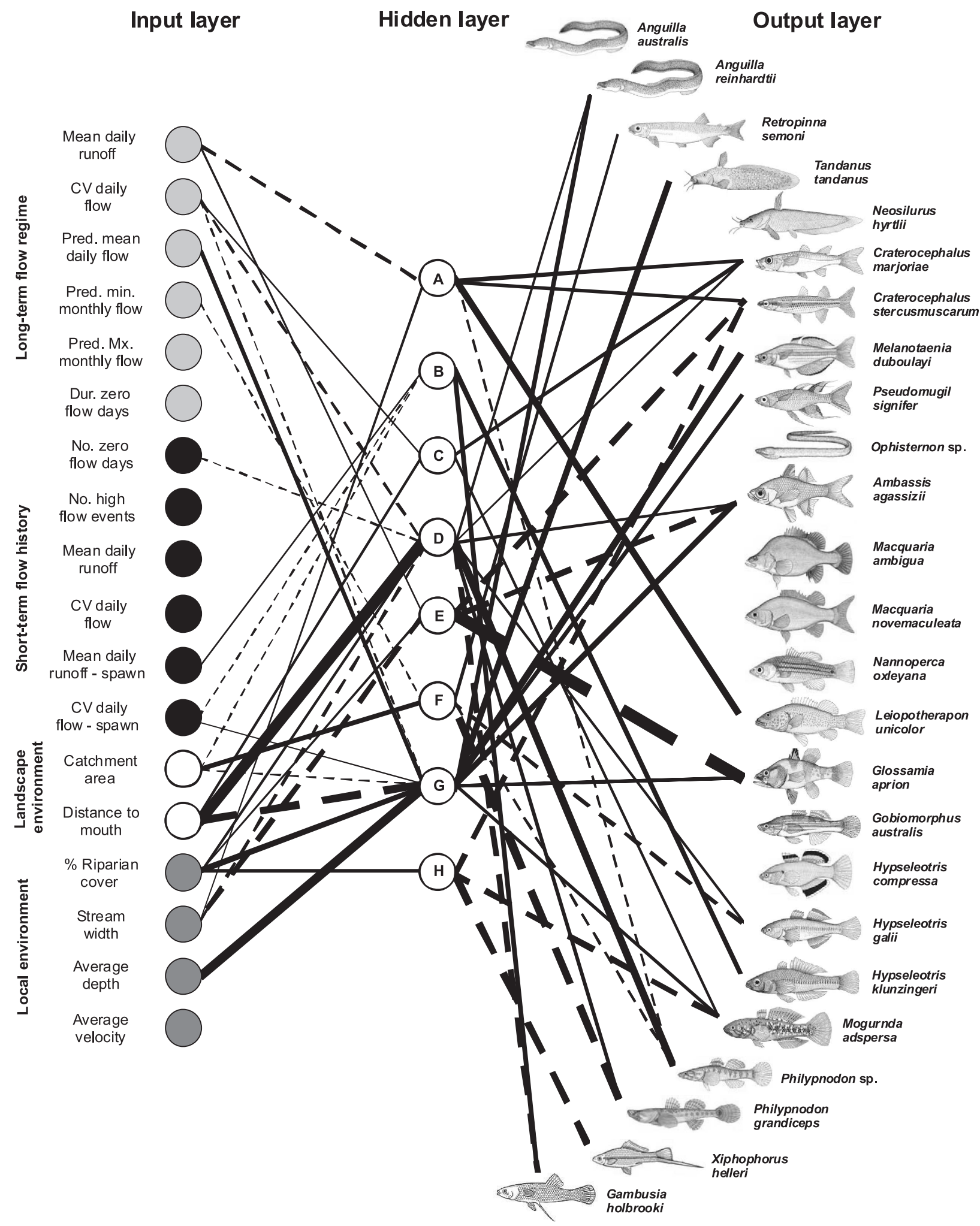


logical factors and into the potential mechanisms likely to influence variation in fish assemblage composition. The importance of interactions between variability of daily flows (long-term) and water depth identified for some fish species suggests that deeper locations are more effectively buffered against changes in habitat structure and quality associated with varying water levels than are shallow sites. The interaction between landscape-scale factors and long-term flow predictability suggests that species of gudgeons with benthic habits (Pusey et al. 2004) were more likely to occur at sites in smaller catchments if minimum flows were sufficiently predictable to ensure the availability of suitable benthic habitat over the long term. Our model also revealed the potential for aspects of the short-term flow history to influence the composition of fish assemblages. For example, an increased probability of fish stranding in wider streams with fluctuating water levels is suggested for some species by the negative influence of variable flow conditions interspersed with extended dry periods. In addition, increasing mean daily runoff during the spawning season before sampling increased the probability of occurrence of two species, except when runoff during this period was highly variable; this implies an adverse effect on their capacity to either spawn successfully or to recruit to larger sizes, or both. These positive and negative interactions collectively highlight the importance of long-term flow variables and local-scale habitat characteristics such as stream width and depth, enhanced or ameliorated by a particular catchment setting and recent flow conditions. These relationships are consistent with our knowledge of the ecology of fish assemblages in the region (Pusey et al. (2004) and references therein).

Comparison of model performances for the Mary River showed that species presence-absence was more predictable than both relative abundance and relative biomass. This scaledependent relationship between environmental drivers and different assemblage response variables is expected (see Rahel 1990). Species presence-absence is a less "noisy" signal and less prone to spatial and temporal variation as it involves a local extinction process, not just a shift in abundance or biomass (Strange et al. 1992; Milner et al. 1993; Poff and Allan 1995). Indeed, in our study systems, spatial and temporal variation in fine-grained fish assemblage responses such as abundance and biomass data is much greater than for the coarser-grained measure of fish species presence or absence (Kennard 2005). Hence, it is not surprising that our models more accurately predicted species presence-absence.

The relative importance of the major classes of environmental and hydrological predictor variables was broadly similar for models predicting species occurrences, abundances, and biomass in the Mary River. That short-term flow variables played a comparatively small predictive role was contrary to our expectations, particularly for abundance and biomass data. The recent history of hydrological events has been shown elsewhere to be an important driver of fish abundance patterns via recruitment processes (e.g., Schlosser 1985; King et al. 2003). However, the dynamics of recruitment processes in fishes are highly complex, with environmental and biologically driven variation in abundances of all life stages contributing substantially to variability in final abundance (Bradford 1992). It is possible that the variables we used to quantify antecedent flow conditions were too coarse to represent flow-related changes in factors contributing to recruitment variation. Such factors could include the suitability and temporal stability of spawning sites, habitat condition, and food resource availability for larvae or the sequence of habitats and conditions necessary for juvenile growth and survival. Similarly, the connectivity of habitats in time and space could also be important, but the surrogate indicators we used, such as number of zero flow days or duration of zero flow days before sampling, may not represent connectivity effectively (Scheurer et al. 2003). In addition, our short-term flow predictors were unlikely to capture the influence of flow variation on biotic processes such as predator-prey relationships and competitive interactions among species that, in turn, can have significant effects on fish assemblage structure (Jackson et al. 2001). Furthermore, because we did not attempt to distinguish the independent explanatory effects of each set of environmental and hydrological drivers, the importance of short-term flow variation may have been obscured by covarying predictors at other spatial and temporal scales (although we avoided using highly correlated variables). It would therefore be instructive to compare the results of the present study with those of other methods that can uncover the unique contribution of different variable sets, including variance partitioning methods (e.g., Magalhães et al. 2002; Pont et al. 2005), or to analyze residuals from each stage of a hierarchical analysis (e.g., Olden et al. 2006b).

Evaluation of the transferability of our predictive models showed that the Mary River model based on species presence-absence data more accurately represented speciesenvironment relationships in the Albert River than did models based on species abundances or biomass. This result suggests that although the landscape-scale features that drive the distribution of individual fish species are similar between these rivers, the particular interactions between the influence of landscape, hydrology, and local habitat features that collectively determine abundance and biomass differ between the two rivers. Although the importance of knowing that particular models are transferable is well recognised (Mac Nally 2002), previous modelling work with stream fishes has illustrated that model transferability can vary greatly depending on circumstances. In general, models constructed for one basin rarely perform as well in another basin (e.g., Fausch et al. 1988; Shirvell 1989; Leftwich et al. 1997). Our results support this earlier work but clearly show that model transferability depends on the type of biological response variable modelled. Model transferability may be compromised if the environmental factors that limit species distributions are not included or retained in the models or if they differ between catchments (Leftwich et al. 1997). Variation in species prevalence (i.e., frequency of occurrence) between systems can also affect spatial transferability of predictive models (Mac Nally 2002; Olden et al. 2002), and this may apply to abundance and biomass data as well. These issues highlight the need for a better understanding of the factors responsible for shaping individual species distributions and assemblage structure before catchment-specific models can be applied more broadly.

In conclusion, improved knowledge of ecological responses to the natural and human-altered characteristics of river flow regimes is urgently required to inform water resource man- 
agement (Arthington et al. 2006; Dudgeon et al. 2006). The demands facing managers as they attempt to allocate limited freshwater resources are escalating and exacerbated by limits in our quantitative understanding of how aquatic ecosystems, and their biological communities, respond to environmental conditions (Allan 2004). The complexity and nested arrangement of environmental factors shaping lotic communities makes the construction of useful predictive models a challenging task. Yet, we were able to model both the composition and structure (abundance and biomass) of fish assemblages and to incorporate all species comprising the assemblage simultaneously within a single integrated modelling process. This multispecies approach increases our capacity to detect and synthesise complex biota-environment relationships (Ferrier and Guisan 2006; Olden et al. 2006a). Predictive modeling studies such as ours contribute to a fundamental understanding of river ecosystem functioning in terms of identifying important interactions between flow regime and habitat at local to landscape scales, their effects on fish assemblage structure, and the generality of these relationships.

\section{Acknowledgments}

This study was funded by the Cooperative Research Centre for Freshwater Ecology, Land and Water Australia (formerly Land and Water Research and Development Corporation) and the Australian Rivers Institute. We thank Steve Mackay and Darren Renouf for assistance with field sampling. We appreciate the detailed comments by several anonymous reviewers, which substantially improved this paper. This research project was approved by the Griffith University Ethics Committee for Experimentation on Animals and the applied research protocols used were conducted in accordance with the requirements of this Committee.

\section{References}

Allan, J.D. 2004. Landscapes and riverscapes: the influence of land use on stream ecosystems. Annu. Rev. Ecol. Evol. Syst. 35: 257-84.

Arthington, A.H., Bunn, S.E., Poff, N.L., and Naiman, R.J. 2006. The challenge of providing environmental flow rules to sustain river ecosystems. Ecol. Appl. 16: 1311-1318.

Biggs, B.J.F., Nikora, V.I., and Snelder, T.H. 2005. Linking scales of variability to lotic ecosystem structure and function. River Res. Appl. 21: 283-298.

Bishop, C.M. 1995. Neural networks for pattern recognition. Oxford University Press Inc., New York.

Bradford, M.J. 1992. Precision of recruitment predictions from early life stages of marine fishes. Fish. Bull. 90: 439-453.

Brizga, S.O., Arthington, A.H., Condina, P., Connolly, N., Craigie, N., Kennard, M., Kenyon, R., Loneragan, N., Mackay, S., and Werren, G. 2004. Mary Basin Water Resource Plan (WRP) environmental conditions report. Two vols. Queensland Department of Natural Resources and Mines, Brisbane, Queensland.

Brizga, S.O., Arthington, A.H., Connolly, R., Kennard, M., MacAlister, T., Mackay, S., McCosker, R., McNeill, V., and Udy, J. 2006. Logan Basin Water Resource Plan (WRP) - environmental investigations report. Two vols. Queensland Department of Natural Resources, Mines and Water, Brisbane, Queensland.
Bunn, S.E., and Arthington, A.H. 2002. Basic principles and ecological consequences of altered flow regimes for aquatic biodiversity. Environ. Manag. 30: 492-507.

Colwell, R.K. 1974. Predictability, constancy and contingency of periodic phenomena. Ecology, 55: 1148-1153.

Cushman, S.A., and McGarigal, K. 2004. Patterns in the speciesenvironment relationship depend on both scale and choice of response variables. Oikos, 105: 117-124.

Dudgeon, D., Arthington, A.H., Gessner, M.O., Kawabata, Z., Knowler, D., Lévêque, C., Naiman, R.J., Prieur-Richard, A.-H., Soto, D., and Stiassny, M.L.J. 2006 . Freshwater biodiversity: importance, threats, status, and conservation challenges. Biol. Rev. 81: 163-182.

Fausch, K.D., Hawkes, C.L., and Parsons, M.G. 1988. Models that predict standing crop of stream fish from habitat variables: 1950-85. US Forest Service, Portland, Oregon, General Technical Report PNW-GTR-213.

Fausch, K.D., Torgersen, C.E., Baxter, C.V., and Li, H.W. 2002. Landscapes to riverscapes: bridging the gap between research and conservation of stream fishes. Bioscience, 52: 483-498.

Ferrier, S., and Guisan, A. 2006. Spatial modelling of biodiversity at the community level. J. Appl. Ecol. 43: 393-404.

Fielding, A.H., and Bell. J.F. 1997. A review of methods for the assessment of prediction errors in conservation presence/absence models. Environ. Conserv. 24: 38-49.

Hughes, R.M. 1995. Defining acceptable biological status by comparing with reference conditions. In Biological assessment and criteria: tools for water resource planning and decision making. Edited by W.S. Davis and T.P. Simon. Lewis, Boca Raton, Florida. pp. 31-48.

Humphries, P., King, A.J., and Koehn, J.D. 1999. Fish, flows and flood plains: links between freshwater fishes and their environment in the Murray-Darling River system, Australia. Environ. Biol. Fishes, 56: 129-151.

Jackson, D.A., Peres-Neto, P.R., and Olden, J.D. 2001. What controls who is where in freshwater fish communities: the roles of biotic, abiotic and spatial factors? Can. J. Fish. Aquat. Sci. 58: 157-170.

Kennard, M.J. 2005. A quantitative basis for the use of fish as indicators of river health in eastern Australia. Ph.D. thesis, Faculty of Environmental Sciences, Griffith University, Brisbane, Queensland.

Kennard, M.J., Pusey, B.J., Arthington, A.H., Harch, B.D., and Mackay, S.J. 2006a. Utility of a multivariate modelling method for prediction of freshwater fish assemblages and evaluation of river health. Hydrobiologia, 572: 33-57.

Kennard, M.J., Pusey, B.J., Harch, B.H., Dore, E., and Arthington, A.H. 2006b. Estimating local stream fish assemblage attributes: sampling effort and efficiency at two spatial scales. Mar. Freshw. Res. 57: 635-653.

King, A.J., Humphries, P., and Lake, P.S. 2003. Fish recruitment on floodplains: the roles of patterns of flooding and life history characteristics. Can. J. Fish. Aquat. Sci. 60: 773-786.

Krebs, C.J. 1999. Ecological methodology. 2nd ed. Benjamin/ Cummings, Menlo Park, Calif.

Leftwich, K.N., Angermeier, P.L., and Dolloff, C.A. 1997. Factors influencing behavior and transferability of habitat models for a benthic stream fish. Trans. Am. Fish. Soc. 126: 725-734.

Lowe, W.H., Likens, G.E., and Power, M.E. 2006. Linking scales in stream ecology. Bioscience, 56: 591-597.

Mac Nally, R. 2002. Improving inference in ecological research: issues of scope, scale, and model validation. Comments Theor. Biol. 7: 237-256.

Magalhães, M.F., Batalha, D.C., and Collares-Pereira, M.J. 2002. Gradients in stream fish assemblages across a Mediterranean 
landscape: contributions of environmental factors and spatial structure. Freshw. Biol. 47: 1015-1031.

Magoulick, D.D., and Kobza, R.M. 2003. The role of refugia for fishes during drought: a review and synthesis. Freshw. Biol. 48: 1186-1198.

Marsh, N.A., Stewardson, M.J., and Kennard, M.J. 2003. River analysis package. Cooperative Research Centre for Catchment Hydrology, Monash University, Melbourne, Victoria, Australia. Software available at http://www.toolkit.net.au.

Matthews, W.J., and Marsh-Matthews, E. 2003. Effects of drought on fish across axes of space, time and ecological complexity. Freshw. Biol. 48: 1232-1253.

Merritt, W.S., Letcher, R.A., and Jakeman, A.J. 2003. A review of erosion and sediment transport models. Environ. Model. Softw. 18: 761-799.

Milner, N.J., Wyatt, R.J., and Scott, M.D. 1993. Variability in the distribution and abundance of stream salmonids, and the associated use of habitat models. J. Fish Biol. 43(Suppl. A): 103-119.

Olden, J.D. 2003. A species-specific approach to modeling biological communities and its potential for conservation. Conserv. Biol. 17: 854-863.

Olden, J.D., and Jackson, D.A. 2002. A comparison of statistical approaches for modelling fish species distributions. Freshw. Biol. 47: 1976-1995.

Olden, J.D., Jackson, D.A., and Peres-Neto, P.R. 2002. Predictive models of fish species distributions: a comment on proper validation and chance predictions. Trans. Am. Fish. Soc. 131: 329-336.

Olden, J.D., Joy, M.K., and Death, R.G. 2004. An accurate comparison of methods for quantifying variable importance in artificial neural networks using simulated data. Ecol. Model. 178: 389-397.

Olden, J.D., Joy, M.K., and Death, R.G. 2006a. Rediscovering the species in community-wide predictive modelling. Ecol. Appl. 16: $1449-1460$.

Olden, J.D., Poff, N.L., and Bledsoe, B.P. 2006b. Incorporating ecological knowledge into ecoinformatics: an example of modeling hierarchically structured aquatic communities with neural networks. Ecol. Inform. 1: 33-42.

Poff, N.L., and Allan, J.D. 1995. Functional organization of stream fish assemblages in relation to hydrologic variability. Ecology, 76: 606-627.

Poff, N.L., and Ward, J.V. 1990. Physical habitat template of lotic systems: recovery in the context of historical pattern of spatiotemporal heterogeneity. Environ. Manag. 30: 629-645.
Poff, N.L., Allan, J.D., Bain, M.B., Karr, J.R., Prestegaard, K.L., Richter, B., Sparks, R., and Stromberg, J. 1997. The natural flow regime: a paradigm for riverine conservation and restoration. Bioscience, 47: 769-784.

Pont, D., Hugueny, B., and Oberdorff, T. 2005. Modelling habitat requirement of European fishes: do species have similar responses to local and regional environmental constraints? Can. J. Fish. Aquat. Sci. 62: 163-173.

Pusey, B.J., Kennard, M.J., and Arthington, A.H. 2000. Discharge variability and the development of predictive models relating stream fish assemblage structure to habitat in north-eastern Australia. Ecol. Freshw. Fish. 9: 30-50.

Pusey, B.J., Kennard, M.J., and Arthington, A.H. 2004. Freshwater fishes of north-eastern Australia. CSIRO Publishing, Collingwood, Victoria, Australia.

Queensland Parliamentary Council. 1994. Queensland Fisheries Act. Reprint No. 3C. Office of the Queensland Parliamentary Council, Queensland.

Rahel, F.J. 1990. The hierarchical nature of community persistence: a problem of scale. Am. Nat. 136: 328-344.

Rose, K.A. 2000. Why are quantitative relationships between environmental quality and fish populations so elusive? Ecol. Appl. 10: $367-385$.

Scheurer, J.A., Fausch, K.D., and Bestgen, K.R. 2003. Multiscale processes regulate brassy minnow persistence in a Great Plains river. Trans. Am. Fish. Soc. 132: 840-855.

Schlosser, I.J. 1985. Flow regime, juvenile abundance and the assemblage structure of stream fishes. Ecology, 66: 1484-1490.

Schlosser, I.J. 1991. Stream fish ecology: a landscape perspective. Bioscience, 41: 704-712.

Shirvell, C.S. 1989. Habitat models and their predictive capability to infer habitat effects on stock size. In Proceedings of the National Workshop on Effects of Habitat Alteration on Salmonid Stocks. Edited by C.D. Levings, L.B. Holtby, and M.A. Henderson. Can. Spec. Publ. Fish. Aquat. Sci. No. 105. pp. 173-179.

Simons, M., Podger, G., and Cooke, R. 1996. IQQM — a hydrologic modelling tool for water resource and salinity management. Environ. Softw. 11: 185-192.

Strange, E.M., Moyle, P.B., and Foin, T.C. 1992. Interactions between stochastic and deterministic processes in stream fish community assembly. Environ. Biol. Fishes, 36: 1-15.

Unmack, P.J. 2001. Biogeography of Australian freshwater fishes. J. Biogeogr. 28: 1053-1089. 